\title{
Efeitos do Laser de Baixa Potência Sobre a Dor e Edema no Trauma Tendíneo de Ratos
}

\section{Effects Of The Low Level Laser Over Pain And Edema In Tendon Trauma Of Rats}

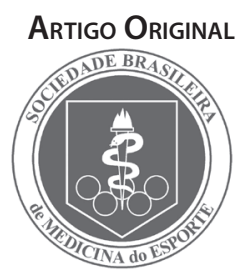

\author{
Gladson Ricardo Flor Bertolini \\ Taciane Stein da Silva ${ }^{1}$ \\ Adriano Polican Ciena ${ }^{1}$ \\ Danilo Lopes da Trindade \\ 1. Laboratório do Grupo de \\ Estudo das Lesões e Recursos \\ Fisioterapêuticos (GELRF) da \\ Universidade Estadual do Oeste \\ do Paraná (Unioeste), Cascavel \\ - Paraná;
}

\section{Endereço para correspondência: \\ Trav. Sebastião Pereira de Camargo, 69, Jardim Padovani \\ 85803-328 - Cascavel, PR. \\ E-mail: gladson_ricardo@yahoo.com.br}

Submetido em 22/11/2007

Versão final recebida em 12/02/2008

Aceito em 22/02/2008

\begin{abstract}
RESUMO
A dor e o edema são sinais, entre outros, que ocorrem durante a fase inflamatória no processo de cura de tendões lesados. A terapia antiinflamatória farmacológica recebe algumas críticas, com relação a seus efeitos deletérios para o reparo. Dessa forma, ganha corpo o uso de recursos físicos para o controle do processo. O objetivo do presente estudo foi avaliar o uso do laser de baixa potência sobre a dor e edema em tendão calcâneo de ratos submetidos a trauma experimental. Foram utilizados 28 ratos Wistar, divididos em quatro grupos: GC - submetido à lesão traumática e ao tratamento placebo; G2 - submetido à lesão e irradiado com

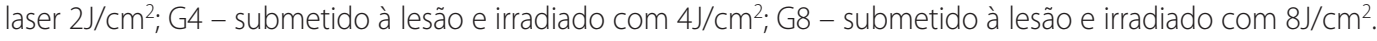
A lesão foi realizada com a queda de um peso sobre a face lateral do tendão calcâneo direito de cada animal, com energia de aproximadamente 0,40J. A dor foi avaliada pelo tempo de elevação da pata (TEP) do animal caminhando durante um minuto, sobre um cilindro metálico com 30cm de diâmetro em 3rpm; a avaliação do edema ocorreu através de paquimetria; os momentos de avaliação foram: pré-lesão, pós-lesão, pós-tratamento, duas horas, oito horas, 24 horas e $5^{\circ}$ dia de lesão. $O$ tratamento com laser 670nm ocorreu de forma pontual e diária. Os resultados mostraram aumentos do TEP e formação de edema em todos os grupos após a lesão; para os grupos tratados houve redução da dor e do edema, fato observado no grupo controle apenas com relação à diminuição de edema no $5^{\circ}$ dia de placebo. Conclui-se que o tratamento com laser de baixa potência diminuiu dor e edema nos animais com trauma tendíneo, de forma dose-dependente.
\end{abstract}

Palavras-chave: Tendão do calcâneo, Laser de baixa potência, avaliação da dor.

\begin{abstract}
During the injured tendons healing process there is the inflammatory phase, which occurs in the presence, among other signs, of pain and edema. The antiinflammatory drug therapy receives some criticism, with respect to its deleterious effects for the repair, thus gain body the use of physical resources for the process control. The aim of this study was to evaluate the use of low level laser therapy on the pain and edema of the rats calcaneus tendon, subjected to experimental trauma. We used 28 rats Wistar, divided into four groups: GC - subjected to traumatic injury and the placebo treatment; G2 - subject to injury and irradiated with laser 2 $\mathrm{J} / \mathrm{cm}^{2} ; \mathrm{G} 4$ - subject to injury and irradiated with $4 \mathrm{~J} / \mathrm{cm}^{2} ; \mathrm{G} 8$ - submitted to injury and irradiated with $8 \mathrm{~J} / \mathrm{cm}^{2}$. The lesion was performed with the fall of a weight on the side of the right calcaneus tendon of each animal, with energy of about $0.40 \mathrm{~J}$. The pain was evaluated by the paw elevation time (PET) for a minute, the animal walking on a metal cylinder with $30 \mathrm{~cm}$ in diameter at $3 \mathrm{rpm}$; the edema evaluation occurred through caliper; moments of the evaluation were: after and before injury, before treatment, 2 hours, 8 hours, 24 hours and $5^{\text {th }}$ injury day. Treatment with laser $670 \mathrm{~nm}$, was so punctual and daily. The results showed increases in PET and formation of edema in all groups after the injury, and for the groups treated there were reducing the pain and edema, being observed in the control group only with the edema reduction in the $5^{\text {th }}$ placebo day. We concluded that the treatment with low level laser therapy decreased the pain and edema of the animals with tendon trauma, in a dose-dependent manner.
\end{abstract}

Keywords: achilles tendon, low level laser therapy, pain measurement.

\section{INTRODUÇÃO}

Tendões são tecidos conectivos frouxos constituídos de fibras colágenas paralelas embebidas dentro de uma matriz extracelular. Essa estrutura organizada permite aos tendões resistir e transmitir grandes forças entre músculos e ossos. Contudo, são propensos a lesões agudas e crônicas, além de sujeitos a movimentos repetidos e degeneração com o tempo(1).

Quando os tendões são lesados, o corpo inicia um processo de cura, que pode ser dividido em fases que se sobrepõem: inflamação, proliferação e remodelamento(1-2). Lesões por sobrecarga em tendões são comuns entre atletas de elite e recreacionais, e podem ser de difícil tratamento ${ }^{(3)}$

Além de atletas, algumas pessoas sentem dor em tendões com o trabalho ou atividades relacionadas e, em casos extremos, sofrem ruptura espontânea do tendão. Cerca de 92\% dos tendões rotos têm alterações degenerativas na matriz, sendo a ruptura o estágio final de processos degenerativos. Uma hipótese para explicar as tendinopatias é o acúmulo de fadiga ou microlesões à matriz, os quais ocorrem diariamente como resultado de atividades habituais. Contudo, os tendões podem reparar o 
dano retornando ao estado sem lesão. Mas, num período de meses ou anos, a lesão não reparada pode resultar na ruptura tendínea(4).

Aspenberg(5) afirma que o papel da inflamação na patologia tendínea é controverso; a maioria das condições patológicas tendíneas ocorre devido à sobrecarga ou degeneração e não tem natureza inflamatória. A tendinose usualmente apresenta lesões intratendíneas localizadas, abundante e patologicamente vascularizadas. A histologia apresenta sinais de degeneração, quebra de colágeno e reparo, com presença de tecido de granulação e brotamento de nervos ricos em substância P. Embora as células inflamatórias estejam apenas moderadamente presentes nesse estágio, assume-se que forte reação inflamatória ocorreu no início do desenvolvimento da lesão. Os tendões com tendinose contêm mais tecido de granulação do que aqueles rotos, mas a dor não é clinicamente associada a aumento no risco de ruptura, apesar de estrutura colagenosa comprometida.

Marsolais et al.(6) relatam que ocorre rápida perda de hidroxiprolina, coincidente com o acúmulo de neutrófilos e macrófagos, suportando a hipótesede que leucócitos fagocitam e digerem o colágeno durante a fase inflamatória. Posteriormente, a concentração de hidroxiprolina gradualmente aumenta, demonstrando que a extensiva síntese de colágeno começa após sete dias. Quando administraram diclofenaco (1 mg/kg) em ratos com tendões calcâneos lesionados, não observaram prevenção da degradação do colágeno e, sim, perda de força tênsil no início da lesão. Questionam, então, o uso de antiinflamatórios para aliviar a inflamação em lesões agudas dos tendões.

Dessa forma, abre-se a possibilidade de uso de recursos físicos, como corrente galvânica, iontoforese, fonoforese, ultra-som terapêutico, eletroestimulação, termoterapia por adição e retirada de calor, massoterapia profunda, mobilização tecidual(2) e laser de baixa potência ${ }^{(7-8)}$, durante o processo de lesão e cura tendínea.

O laser de baixa potência tem indicação em casos de tendinopatia, devido a características como: estimulação à proliferação de fibroblastos $^{(9)}$, redução do processo inflamatório ${ }^{(10)}$, porém com aceleração na síntese de colágeno ${ }^{(11-12)}$, facilitação na formação de fibrilas colágenas e aumento na força tênsil final de tendões em processo de reparo(13-14) Contudo, Elwakil ${ }^{(15)}$ salienta que não há método de tratamento que tenha provado acelerar a taxa de cura ou melhorar a qualidade de regeneração de tendões.

Fung et al. ${ }^{(16)}$ avaliaram os efeitos do laser sobre parâmetros biomecânicos, três e seis semanas, na cura de ligamentos colaterais mediais secionados de ratos. Utilizaram logo após a secção do ligamento o laser de $660 \mathrm{~nm}$, em aplicação única com $31,6 \mathrm{~J} / \mathrm{cm}^{2}$ ou $63,2 \mathrm{~J} / \mathrm{cm}^{2}$. Observaram que a força tênsil final e a rigidez nos animais tratados foi maior do que as naqueles do controle. A força tênsil final do laser foi comparável ao de animais sujeitos ao simulacro do procedimento cirúrgico. Posteriormente, Fung et al. ${ }^{(17)}$, com metodologia semelhante ao do trabalho anterior, avaliaram parâmetros ultra-estruturais das fibrilas de colágeno; observaram que o laser restaurou o tamanho das fibrilas de colágeno após três e seis semanas de secção ligamentar.

Porém, o uso da terapia laser apresenta controvérsias, devido à grande divergência nos parâmetros dosimétricos e às discrepâncias nos achados ${ }^{(9,16-18)}$. Visto o exposto acima, objetivou-se, no presente estudo, avaliar o uso do laser de baixa potência em dois aspectos do processo de lesão/reparo (dor e edema) de tendão calcâneo de ratos submetidos a trauma experimental.

\section{MATERIAL E MÉTODOS}

\section{Grupos experimentais}

Foram utilizados 28 ratos Wistar machos, com peso de 320,30 \pm $20,22 \mathrm{~g}$ e idade $12 \pm 2$ semanas, mantidos em fotoperíodo de $12 \mathrm{~h}$, com água e ração ad libitum. Os animais foram divididos aleatoriamente em quatro grupos:

- GC $(n=7)$ - submetido à lesão traumática em tendão calcâneo direito e ao tratamento placebo (simulacro);

- G2 ( $n=7)$ - submetido à lesão traumática e irradiado com laser $2 \mathrm{~J} / \mathrm{cm}^{2}$;

- G4 ( $n=7)$ - submetido à lesão traumática e irradiado com laser $4 \mathrm{~J} / \mathrm{cm}^{2}$

- G8 $(n=7)$ - submetido à lesão traumática e irradiado com laser $8 \mathrm{~J} / \mathrm{cm}^{2}$

O projeto foi conduzido segundo as normas internacionais de ética em experimentação animal(19).

\section{MODELO EXPERIMENTAL DE TRAUMA NO TENDÃO CALCÂNEO}

Os animais foram sedados com inalação de éter etílico e posteriormente posicionados em decúbito lateral esquerdo, expondo a região lateral do tendão calcâneo direito ao trauma. Para a produção da lesão traumática foi utilizado um equipamento projetado pelo Departamento de Engenharia Civil da Unioeste. O mesmo consistiu de um peso $(575 \mathrm{~g})$ partindo sempre de uma mesma altura inicial $(7 \mathrm{~cm})$ em queda sobre a face lateral do tendão calcâneo direito de cada animal, perfazendo uma energia de impacto de aproximadamente 0,40J.

\section{TESTE DE INCAPACIDADE FUNCIONAL (TEMPO DE ELEVAÇÃO DA PATA - TEP)}

O teste caracterizou-se basicamente por um cilindro metálico em movimento, e um programa de computador com conexão a uma bota metálica adaptada à pata do animal, descrito originalmente por Tonussi e Ferreira ${ }^{(20)}$.

Os animais deambularam sobre o cilindro, de aproximadamente $30 \mathrm{~cm}$ de diâmetro recoberto por tela de aço inoxidável que, por meio de um motor elétrico, realizava três rotações por minuto. Nos membros posteriores dos animais eram adaptadas botas, confeccionadas com metal, que conduziam a informação da pata direita, por meio de um fio, a um computador, o qual possui um programa que mostra os valores de tempo de pata no ar do animal deambulando sobre o cilindro em um minuto; o membro posterior esquerdo também foi mantido conectado a uma bota, porém sem entrada de informações para o computador.

O experimento iniciou-se com o treino dos animais sobre o cilindro e no dia seguinte foram anotados os valores de tempo da marcha normal. Em seguida, houve o procedimento traumático, ocorrendo reavaliações logo após a recuperação da sedação do animal (o que demorava aproximadamente cinco minutos), ou seja, pós-lesão, depois o primeiro tratamento ou simulacro (no caso do grupo controle), após duas, oito e 24 horas da lesão (antes de ocorrer a segunda terapia) e, finalmente, após o $5^{\circ}$ dia de lesão. Normalmente, os animais sem alterações mantêm em marcha a pata no ar em torno de 10 segundos; os animais com dor apresentam maiores tempos de pata no $\operatorname{ar}^{(21)}$

\section{AVALIAÇÃO DO EDEMA NO TENDÃO CALCÂNEO}

Previamente à lesão, avaliou-se o diâmetro dos tendões calcâneos, em seu terço médio, com paquímetro posicionado médio-lateralmente. Essa forma de avaliação foi realizada logo após o teste de incapacidade funcional, nos mesmos períodos de avaliação. 


\section{APLICAÇÃO DO LASER}

Logo depois de transcorrida a avaliação do momento pós-lesão, iniciou-se o tratamento dos tendões lesados, utilizando o laser da marca Bioset ${ }^{\circ}$, com comprimento de onda de 670 nanômetros, 30 mW de potência, de forma pontual e contínua, especificamente sobre o local do trauma, sendo os animais mantidos em contensor de PVCtermoplástico, descrito por Lirani(22). Cada grupo foi irradiado com a densidade de energia correspondente; para cada $1 \mathrm{~J} / \mathrm{cm}^{2}$ depositado, o equipamento demorava 3s;o grupo controle sofreu procedimento semelhante, porém, com o equipamento desligado.

O procedimento ocorreu no decorrer de cinco dias consecutivos, incluindo o dia da lesão, perfazendo um total de cinco terapias, com intervalo de 24 horas entre as aplicações. O equipamento utilizado foi previamente aferido para averiguação da potência de emissão. Ao quarto dia pós-lesão, findas as aplicações laser, os animais foram mortos, sendo previamente sedados com éter etílico e decapitados em guilhotina.

\section{ANÁLISE DOS RESULTADOS}

Os resultados foram expressos e analisados por meio da estatística descritiva e inferencial, utilizando média, desvio-padrão, análise de variância com e sem medidas repetidas, e pós-teste de Tukey, com nível de significância $a=0,05$.

\section{RESULTADOS}

\section{Tempo de elevação da pata}

Os valores encontrados para TEP são apresentados na tabela 1 e a figura 1 apresenta graficamente as relações dentro dos grupos.

Tabela 1. Valores do TEP (média e desvio-padrão), em segundos, para os grupos estudados, de acordo com o momento de avaliação.

\begin{tabular}{c|c|c|c|c|c|c|c}
\hline & Pré & Pós & TT IMED & 2h & $\mathbf{8 h}$ & $\mathbf{2 4 h}$ & $\mathbf{5}^{\circ} \mathbf{d}$ \\
\hline $\mathrm{GC}$ & $9,72 \pm 0,83$ & $19,00 \pm 5,25$ & $17,15 \pm 2,74$ & $17,51 \pm 3,32$ & $16,15 \pm 1,32$ & $14,81 \pm 1,83$ & $16,85 \pm 3,46$ \\
\hline $\mathrm{G} 2$ & $10,22 \pm 0,48$ & $21,86 \pm 3,24$ & $21,81 \pm 4,19$ & $16,56 \pm 1,84$ & $17,22 \pm 2,85$ & $14,23 \pm 1,58$ & $8,45 \pm 2,91$ \\
\hline $\mathrm{G} 4$ & $8,72 \pm 1,07$ & $20,31 \pm 3,42$ & $18,69 \pm 4,38$ & $17,59 \pm 2,28$ & $18,42 \pm 2,86$ & $14,94 \pm 3,04$ & $8,88 \pm 1,32$ \\
\hline $\mathrm{G} 8$ & $9,19 \pm 0,69$ & $20,86 \pm 2,81$ & $18,59 \pm 4,33$ & $18,48 \pm 4,31$ & $15,77 \pm 2,67$ & $15,22 \pm 2,58$ & $10,24 \pm 1,53$ \\
\hline
\end{tabular}

Para GC, todos os momentos avaliados comparados com o prélesão apresentaram aumento significativo dos tempos em relação aos pós-lesão, após tratamento imediato, após duas horas, oito horas, 24 horas e $5^{\circ}$ dia, respectivamente. Ao realizar as comparações entre os valores após lesão, com os seguintes, não foram encontradas variações significativas. G2 apresentou, ao comparar pré-lesão com os momentos seguintes, variação significativa até duas horas, mas a partir de oito horas tal variação não foi mais significativa. Nas comparações com os valores pós-lesão, não houve variação significativa com o tratamento imediato, mas ocorreu com os momentos seguintes.

Para G4, as comparações com os valores pré-lesão não foram significativas apenas no $5^{\circ}$ dia. Ao comparar com pós-lesão, houve variação significativa a partir de 24 horas. E para G8, as comparações entre prélesão e os outros momentos foram significativas, com exceção do $5^{\circ}$ dia. Na comparação do pós-lesão com os seguintes, houve variação significativa a partir de oito horas.

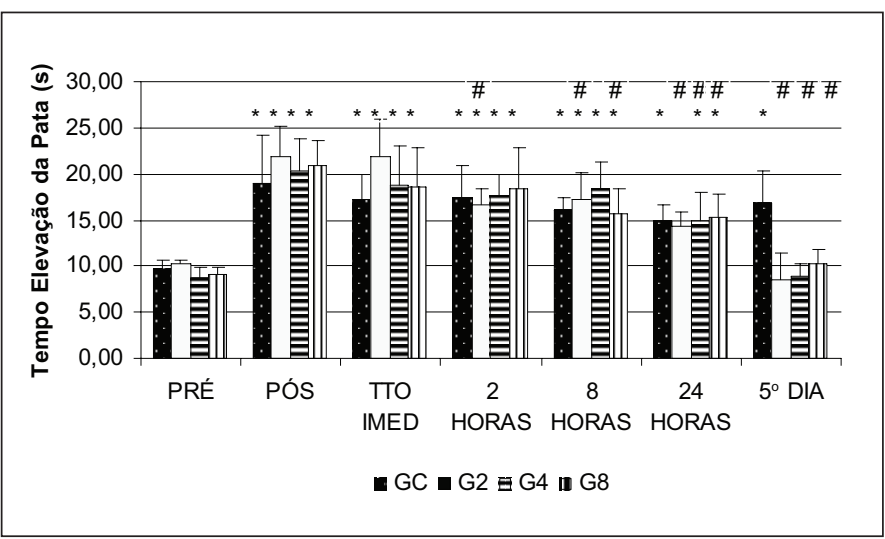

Figura 1. Avaliação do tempo de elevação da pata (s) para os grupos: controle (GC), tratado com $2 \mathrm{~J} / \mathrm{cm}^{2}$ (G2), tratado com $4 \mathrm{~J} / \mathrm{cm}^{2}$ (G4) e tratado com $8 \mathrm{~J} / \mathrm{cm}^{2}$ (G8). * Diferença significativa comparado com o momento pré-lesão. \# Diferença significativa comparado com o momento pós-lesão.

A comparação entre grupos apresentou diferença significativa ( $p<$ 0,01 ) apenas para a comparação pré-lesão entre o grupo tratado com $2 \mathrm{~J} / \mathrm{cm}^{2}$ e tratado com $4 \mathrm{~J} / \mathrm{cm}^{2}$ e, no $5^{\circ}$ dia, diferenças significativas entre o grupo controle e os outros três grupos.

\section{AVALIAÇÃO DO EDEMA}

Os valores obtidos na avaliação do edema, pela paquimetria são apresentados na tabela 1; a figura 1 mostra graficamente as relações dentro dos grupos.

Tabela 2. Valores do edema (média e desvio-padrão), em centímetros, para os grupos estudados, de acordo com o momento de avaliação.

\begin{tabular}{c|c|c|c|c|c|c|c}
\hline & Pré & Pós & TT IMED & $\mathbf{2 h}$ & $\mathbf{8 h}$ & $\mathbf{2 4 h}$ & $\mathbf{5}^{\circ} \mathbf{d}$ \\
\hline GC & $0,26 \pm 0,01$ & $0,59 \pm 0,07$ & $0,62 \pm 0,09$ & $0,61 \pm 0,07$ & $0,56 \pm 0,05$ & $0,53 \pm 0,04$ & $0,38 \pm 0,05$ \\
\hline G2 & $0,25 \pm 0,01$ & $0,67 \pm 0,03$ & $0,64 \pm 0,03$ & $0,61 \pm 0,03$ & $0,59 \pm 0,04$ & $0,55 \pm 0,05$ & $0,33 \pm 0,04$ \\
\hline G4 & $0,26 \pm 0,01$ & $0,50 \pm 0,05$ & $0,60 \pm 0,06$ & $0,53 \pm 0,06$ & $0,53 \pm 0,05$ & $0,50 \pm 0,05$ & $0,32 \pm 0,02$ \\
\hline G8 & $0,26 \pm 0,03$ & $0,66 \pm 0,03$ & $0,63 \pm 0,05$ & $0,57 \pm 0,05$ & $0,57 \pm 0,04$ & $0,53 \pm 0,03$ & $0,34 \pm 0,04$ \\
\hline
\end{tabular}

Para GC, em todos os momentos avaliados, ao comparar com o momento pré-lesão, houve aumento significativo dos diâmetros. Ao realizar as comparações entre os valores após lesão com os seguintes, foi encontrada variação significativa apenas no $5^{\circ}$ dia. G2 apresentou, ao comparar pré-lesão com os momentos seguintes, variação significativa em todos os momentos. Nas comparações com os valores pós-lesão, apenas ao relacionar com o tratamento imediato não houve variação significativa.

Para G4, as comparações com os valores pré-lesão não mostraram variação significativa apenas no $5^{\circ}$ dia. Ao comparar com pós-lesão, houve variação significativa apenas com relação ao tratamento imediato e com o $5^{\circ}$ dia. E para G8, as comparações entre pré-lesão e os outros momentos foram significativas para todos. Na comparação do pós-lesão com os seguintes, não houve variação significativa apenas ao comparar com o tratamento imediato.

Na comparação entre grupos, observaram-se diferenças significativas no momento pós-lesão, do controle com G2 e G4, também entre G2 e G4, e entre G4 e G8. Após a 5 a terapia, também foram encontradas variações significativas entre GC e G4. 


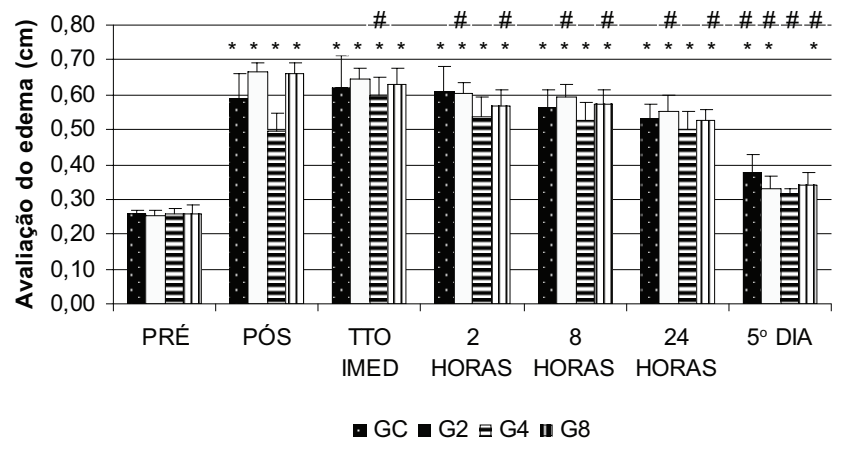

Figura 2. Avaliação do edema no tendão calcâneo $(\mathrm{cm})$ para os grupos: controle (GC), tratado com $2 \mathrm{~J} / \mathrm{cm}^{2}$ (G2), tratado com $4 \mathrm{~J} / \mathrm{cm}^{2}$ (G4) e tratado com $8 \mathrm{~J} / \mathrm{cm}^{2}$ (G8). * Diferença significativa comparado ao momento pré-lesão. \# Diferença significativa comparado com o momento pós-lesão.

\section{DISCUSSÃO}

As células tendíneas têm um ponto de tensão normal e alterações neste ponto engatilham respostas biológicas. Porém, modelos animais com cargas controladas têm falhado em produzir alterações degenerativas na matriz tendínea; tal informação tem grande importância em estudos de modulação farmacológica para tratar a doença ou prevenir sua progressão(4). Alguns modelos experimentais são utilizados para avaliar as patologias e reparo tendíneo, como injeção de carragenina e $\mathrm{PGE}_{1}{ }^{(5)}$; injeção de colagenase ${ }^{(3,6)}$; ruptura parcial longitudinal(14); secção transversa parcial(23); e, secção transversa total|(15).

Visto que as lesões tendíneas podem ser classificadas em agudas ou crônicas e diretas ou indiretas, e que as lesões agudas diretas ocorrem devido à contusão não penetrante ${ }^{(1)}$, no presente estudo, o modelo de trauma tendíneo, semelhante ao apresentado por Salate et al. ${ }^{(7)}$, mostrou-se uma ferramenta útil para avaliação de duas características do processo inflamatório, visto que ocorreu presença da dor e de edema em todos os grupos submetidos ao trauma ${ }^{(20,24)}$.

O processo lesão/reparo é dividido em três estágios: inflamação, proliferação e remodelamento(2) . Durante o primeiro estágio, as prostaglandinas têm um importante papel no acúmulo de células inflamatórias e os leucócitos podem exacerbar a lesão inicial; acredita-se que reduzindo a produção de $\mathrm{PGE}_{2}$ e acúmulo de células inflamatórias, ocorrerá redução na lesão do tendão(6). Assim, o laser de baixa potência mostra-se como uma ferramenta em potencial nesses casos, visto os efeitos de redução nos níveis de $C O X-2^{(25)}$ e $\mathrm{PGE}_{2}{ }^{(26)}$, além de redução do edema inflamatório por provável ação na liberação de hormônios adrenais $^{(27)}$. Mas diferentemente dos antiinflamatórios não hormonais ${ }^{(6)}$, o laser poderia não apresentar atraso do reparo tendíneo, vista sua importante ação no aumento de fibras colágenas e na força tênsil final ${ }^{(12-14)}$. Tal característica foi observada no presente estudo, pois, para os grupos tratados, houve diminuição significativa da dor e edema.

$\mathrm{Ng}$ et al. (28-29) demonstraram que, em ligamentos colaterais mediais de joelhos de ratos lesionados, o laser de baixa potência aumentou o diâmetro das fibrilas de colágeno, melhorando a força e rigidez do ligamento, após três semanas de reparo. Demir et al. ${ }^{(14)}$ avaliaram o uso do laser $904 \mathrm{~nm}\left(1 \mathrm{~J} / \mathrm{cm}^{2}\right)$, ultra-som terapêutico $1 \mathrm{MHz}\left(0,5 \mathrm{~W} / \mathrm{cm}^{2}\right)$ e a combinação das terapias, sobre a cura de tendões em ratos, lesionados longitudinalmente. Avaliaram o conteúdo de hidroxiprolina e força para quebra do tendão, em animais tratados durante nove dias. Relatam que todas as formas de tratamento produziram ganhos significativos nos parâmetros bioquímicos e biomecânicos, mas não houve somação significativa das terapias.
Gonçalves et al. ${ }^{(12)}$ demonstraram que o laser HeNe apresentou efeitos positivos sobre a dinâmica de cura de feridas cutâneas em camundongos, produzindo aumento na síntese de colágeno e aumentando os valores da celularidade local nos primeiros três dias da lesão, inclusive restaurando a diminuição da celularidade induzida por drogas antiinflamatórias. Contudo, Bayat et al. ${ }^{(10)}$ observaram que o laser apresentou diminuição do conteúdo de macrófagos e aumento na quantidade de vasos sanguíneos em sete e 16 dias após indução de queimaduras de segundo grau em ratos.

No presente estudo, não foram avaliados aspectos histológicos do reparo. Mas a diminuição nos parâmetros inflamatórios sugere que ocorreu diminuição do mesmo, o que está de acordo com os achados de Elwakil ${ }^{(15)}$, que avaliou o uso do laser HeNe $\left(632,8 \mathrm{~nm}, 1 \mathrm{~J} / \mathrm{cm}^{2}\right.$, diário até o $14^{\circ}$ dia de PO) sobre o processo de cura de tendões calcâneos, de coelhos, cirurgicamente reparados. Na avaliação histopatológica, observou que o laser produziu alterações fibroproliferativas bem organizadas, com bandas de colágeno alinhadas e, comparado com o grupo controle, havia marcada redução na reação inflamatória, sem reação granulomatosa de corpo estranho proeminente. Ao avaliar biomecanicamente, relata que o grupo tratado apresentou melhora nas propriedades biomecânicas, comparado com o grupo controle.

Carrinho et al. ${ }^{(8)}$ avaliaram os efeitos do laser de 685 e de $830 \mathrm{~nm}$, em 3 e 10J/ $\mathrm{cm}^{2}$, no reparo de tendões calcâneos de camundongos. Observaram que os dois comprimentos de ondas, nas duas doses utilizadas, aceleraram o processo de cura do tendão calcâneo após a tenotomia, com melhores resultados encontrados com $685 \mathrm{~nm}$ e $3 \mathrm{~J} / \mathrm{cm}^{2}$; a segunda melhor resposta foi de $830 \mathrm{~nm}$ com 3J/cm² e $685 \mathrm{~nm}$ com $10 \mathrm{~J} / \mathrm{cm}^{2}$, seguida por 830nm com $10 \mathrm{~J} / \mathrm{cm}^{2}$.

Neste estudo utilizou-se apenas um comprimento de onda (670nm), o qual é visível e vermelho. Ele apresentou efeitos significativos na redução da dor e edema, em pelo menos algum momento de avaliação. Mas, ressalta-se como limitação a não comparação de diferentes comprimentos de onda, o que, segundo Karu ${ }^{(30)}$, pode interferir com as bandas de absorção e. conseqüentemente, efeitos terapêuticos. Sugere-se tal inserção em futuros estudos.

Salate et al. ${ }^{(7)}$ analisaram duas diferentes potências (10 mW e 40mW), em tempos de irradiação semelhantes (10s) de laser 660nm, sobre a angiogênese após ruptura parcial de tendões calcâneos de ratos. Relatam que a de $40 \mathrm{~mW}$ promoveu aumento na neovascularização após três dias e, para $10 \mathrm{~mW}$, os efeitos ocorreram após cinco dias de irradiação. No 70 dia o grupo de $40 \mathrm{~mW}$ apresentou menor número de microvasos do que no $5^{\circ}$ dia, porém, ainda maior do que os valores do controle. Concluíram que o laser promove a neovascularização em tendões lesados.

Para o presente estudo, a potência foi única, em 30mW, não sendo possível comparar alterações neste parâmetro, mas, visto que foram utilizadas três diferentes fluências, além de um grupo placebo, podese analisar o efeito do laser de baixa potência em 2, 4 e $8 \mathrm{~J} / \mathrm{cm}^{2}$. Em face da falta de dosimetria específica para o laser de baixa potência, optou-se neste estudo por doses que variam entre baixas a moderadas, e que são frequentemente utilizadas na prática clínica fisioterapêutica e possuem respaldo na literatura específica ${ }^{(7-9,11-15,28-29)}$, visando testá-las nos parâmetros analisados.

Para o grupo placebo, a dor, avaliada através do TEP, teve comportamento bem peculiar, com aumento dos tempos após a lesão, que não diminuíram significativamente em nenhum momento avaliado, muito menos retornaram aos valores basais. Já para o edema, apesar de não ter ocorrido volta ao valor basal, comparando-se os valores pós-lesão com o $5^{\circ}$ dia de tratamento, ocorreu diminuição significativa do mesmo. 
A menor dose produziu restauração dos valores de TEP em 24 horas, mantendo-se dessa forma no $5^{\circ}$ dia, tendo atingido diminuição da dor após duas horas da irradiação (quando se comparou com os valores pós-lesão). Quanto ao edema, apesar de não ter ocorrido retorno aos valores iniciais, a partir de duas horas foi encontrada redução significativa. Foi essa a dose em que foram obtidos os efeitos mais importantes para os parâmetros avaliados.

Para $4 \mathrm{~J} / \mathrm{cm}^{2}$ os resultados foram mais inconsistentes, não sendo tão bons quanto $2 \mathrm{~J} / \mathrm{cm}^{2}$, pois tal dose, apesar de ter produzido retorno aos valores basais do TEP no $5^{\circ}$ dia, produziu diminuição na dor apenas em 24 horas e $5^{\circ}$ dia. Para o edema, restaurou os valores basais no $5^{\circ} \mathrm{dia}$, mas, em seguida ao tratamento imediato, houve aumento significativo, ao comparar com o pós-lesão. Tal fato poderia ser explicado, por aumento no extravasamento líquido dos vasos após o uso do laser, mas isso não ocorreu com 2 e $8 \mathrm{~J} / \mathrm{cm}^{2}$. Sugerem-se, então: um possível efeito dependente da dose; erros na forma de avaliação com o paquímetro; ou, apesar de a lesão ser seriada, com metodologia semelhante em todos os animais, nesse grupo houve maior dano vascular tendíneo e, por isso, maior formação de edema; ou, o mais provável, atraso na formação do edema, pois no momento pós-lesão houve diferença significativa ao comparar com os outros três grupos, o que não houve nos períodos subseqüentes de avaliação, ocorrendo diferença apenas no $5^{\circ}$ dia ao comparar com o controle.

\section{REFERÊNCIAS BIBLIOGRÁFICAS}

1. Lin TW, Cardenas L, Soslowsky LJ. Biomechanics of tendon injury and repair. J Biomech 2004;37:865-77.

2. Sandrey MA. Acute and chronic tendon injuries: factors affecting the healing response and treatment. J Sport Rehabil 2003;12:70-91.

3. Dahlgren LA, Mohammed HO, Nixon AJ. Expression of insulin-like growth factor binding proteins in healing tendon lesions. J Orthop Res 2006;24:183-92.

4. Archambault J. Tendon micromechanics and research methods in tendinopathy. J Musculoskel Neuron Interact 2003;3:326-8.

5. Aspenberg P. Is inflammation harmless to loaded tendons? J Appl Physiol 2007;102:3-4.

6. Marsolais D, Côté CH, Frenette J. Nonsteroidal anti-inflammatory drug reduces neutrophil and macrophage accumulation but does not improve tendon regeneration. Lab Invest 2003;83:991-9.

7. Salate ACB, Barbosa G, Gaspar P, Koeke PU, Parizotto NA, Benze BG, et al. Effect of In-Ga-Al-P diode laser irradiation on angiogenesis in partial ruptures of Achilles tendon in rats. Photomed Laser Surg 2005;23:470-5.

8. Carrinho PM, Renno ACM, Koeke P, Salate ACB, Parizotto NA, Vidal BC. Comparative study using 685$\mathrm{nm}$ and $830-\mathrm{nm}$ lasers in the tissue repair of tenotomized tendons in the mouse. Photomed Laser Surg 2006;24:754-8.

9. Pereira AN, Eduardo CP, Matson E, Marques MM. Effect of low-power laser irradiation on cell growth and procollagen synthesis of cultured fibroblasts. Lasers Surg Med 2002;31:263-7.

10. Bayat M, Vasheghani MM, Razavi N, Taheri S, Rakhshan M. Effect of low-level laser therapy on the healing of second-degree burns in rats: a histological and microbiological study. J Photochem Photobiol B 2005;78:171-7.

11. Reddy GK, Stehno-Bittel L, Enwemeka CS. Laser photostimulation of collagen production in healing rabbit achilles tendons. Lasers Surg Med 1998;22:281-7.

12. Gonçalves WLS, Souza FM, Conti CL, Cirqueira JP, Rocha WA, Pires JGP, et al. Influence of He-Ne laser therapy on the dynamics of wound healing in mice treated with anti-inflammatory drugs. Braz J Med Biol Res 2007;40:877-84.

13. Bayat M, Delbari A, Almaseyeh MA, Sadeghi Y, Bayat M, Reziae F. Low-level laser therapy improves early healing of medial collateral ligament injuries in rats. Photomed Laser Surg 2005;23:556-60.

14. Demir H, Menku P, Kirnap M, Calis M, Ikizceli I. Comparison of the effects of laser, ultrasound, and combined laser + ultrasound treatments in experimental tendon healing. Lasers Surg Med 2004;35:84-9.

15. Elwakil TF. An in-vivo experimental evaluation of He-Ne laser photostimulation in healing Achilles tendons. Lasers Med Sci 2007;22:53-9.

16. Fung DTC, Ng GYF, Leung MCP, Tay DKC. Therapeutic low energy laser improves the mechanical strength of repairing medial collateral ligament. Lasers Surg Med 2002;31:91-6.
O grupo de $8 \mathrm{~J} / \mathrm{cm}^{2}$ conseguiu retorno aos valores basais de TEP apenas no $5^{\circ}$ dia, mas obteve diminuição da dor a partir de oito horas após a lesão. Para o edema, apesar de não ter ocorrido o retorno aos valores de base, a partir de duas horas do trauma, já houve redução significativa do mesmo.

Salienta-se que, na comparação entre grupos, houve diferença significativa para O TEP ao $5^{\circ}$ dia; ao comparar com os tratados, o controle apresentou valores maiores. Para a formação de edema, G4 apresentou diferenças, o que já foi discutido anteriormente.

\section{CONCLUSÃO}

Conclui-se que o laser de baixa potência, $670 \mathrm{~nm}$, produziu diminuição de dor e edema, em animais com tendão calcâneo traumatizado, e tal ação foi dose-dependente.

\section{AGRADECIMENTOS}

À Universidade Estadual do Oeste do Paraná (Unioeste) e ao Hospital Universitário do Oeste do Paraná (HUOP), pelo financiamento parcial deste estudo.

Todos os autores declararam não haver qualquer potencial conflito de interesses referente a este artigo.
17. Fung DTC, Ng GYF, Leung MCP, Tay DKC. Effects of a therapeutic laser on the ultrastructural morphology of repairing medial collateral ligament in a rat model. Lasers Surg Med 2003;32:286-93.

18. Lomelí-Rivas Á, Krötzsch E, Michtchenko A. Efecto de la estimulación láser de $\lambda=650 \mathrm{~nm}$, utilizando dosis de uso clínico, sobre la proliferación de fibroblastos humanos cultivados. Rev Mex Med Fís Rehabil 2003;15:69-71.

19. Andersen ML, D'Almeida V, Ko GM, Kawakami R, Martins PJF, Magalhães LE, et al. Princípios éticos e práticos do uso de animais de experimentação. São Paulo: UNIFESP - Universidade Federal de São Paulo, 2004.

20. Tonussi CR, Ferreira SH. Rat knee-joint carrageenin incapacitation test: an objective screen for centra and peripheral analgesics. Pain 1992;49:421-7.

21. Martins MA, Bastos LC, Tonussi CR. Formalin injection into knee joints of rats: pharmacologic characterization of a deep somatic nociceptive model. J Pain 2006;7:100-7.

22. Lirani APR. Estudo comparativo dos efeitos do ultra-som e do laser de baixa intensidade, no reparo ósseo de tíbia de ratos (Dissertação de Mestrado). Escola de Engenharia de São Carlos / Faculdade de Medicina de Ribeirão Preto. Universidade de São Paulo, 2004.

23. Grewal R, Saw SSC, Varitimidus S, Bastidas JA, Sotereanos DG, Fischer KJ. Evaluation of passive and active rehabilitation and of tendon repair for partial tendon lacerations after three weeks of healing in canines. Clin Biomech 2006;21:804-9.

24. Gould D, Yousaf N, Fatah R, Subang MC, Chernajovsky Y. Gene therapy with an improved doxycyclineregulated plasmid encoding a tumour necrosis factor-al pha inhibitor in experimental arthritis. Arthritis Res Ther 2007;9:R7. Disponível em: http://arthritis-research.com/content/9/1/R7. Acesso em: 01 de setembro de 2007

25. Albertini R, Aimbire F, Villaverde AB, Silva Jr JA, Costa MS. COX-2 mRNA expression decreases in the subplantar muscle of rat paw subjected to carrageenan-induced inflammation after low level laser therapy. Inflamm Res 2007;56:228-9.

26. Mizutani K, Musya Y, Wakae K, Kobayashi T, Tobe M, Taira K, et al. A clinical study on serum prostaglandin $E_{2}$ with low-level laser therapy. Photomed Laser Surg 2004;22:537-9.

27. Albertini R, Aimbire FS, Correa FI, Ribeiro W, Cogo JC, Antunes E, et al. Effects of different protoco doses of low power gallium-aluminum-arsenate ( $\mathrm{Ga}-\mathrm{Al}-\mathrm{As}$ ) laser radiation $(650 \mathrm{~nm})$ on carrageenan induced rat paw ooedema. J Photochem Photobiol B 2004;74:101-7.

28. Ng GYF, Fung DTC, Leung MCP, Guo X. Comparison of single and multiple applications of gaalas laser on rat medial collateral ligament repair. Lasers Surg Med 2004;34:285-9.

29. Ng GYF, Fung DTC, Leung MCP, Guo X. Ultrastructural comparison of medial collateral ligament repair after single or multiple applications of GaAlAs laser in rats. Lasers Surg Med 2004;35:317-23.

30. Karu, T. Primary and secondary mechanisms of action of visible-to-near IR radiation on cells. J Photochem Photobiol B 1999;49:1-17. 